\title{
Teaching Programming with the Help of Robotic Kits in Middle School: Concrete Experience of Cycles and Conditions
}

\author{
Halil Senturk \\ Ministry of National Education, Karlıova Kantarkaya Secondary School, Bingol, Turkey \\ E-mail: halilsenturk411@gmail.com \\ Orcid.org/0000-0002-8672-8048
}

\begin{abstract}
The main purpose of this study is to determine the source of the problems experienced in coding teaching in middle school education with information technologies and software course and to plan studies to eliminate it. First of all, interviews were made with the students to reveal the problem and it was revealed that the students mostly had difficulties about "cycles" and "conditions" and could not grasp these issues. Then, an achievement test was applied for the academic reflections of the situation and an attitude scale was applied to determine the attitudes of the students. These collected data were analyzed and needs were determined. With the literature review for the solution of the problem, it was decided to include robotic applications, taking into account factors such as students' age, readiness level, environment, and cost. In the study, the groups to be taught were determined, and the measurement tools whose validity and reliability were ensured were included. A total of 50 students, each consisting of 25 students, 1 experimental group and 1 control group took part in the study. In this process, in order to collect data, the attitude scale and achievement test towards programming were applied to the control group, while the robotic attitude scale and achievement test were applied to the experimental group. As a result of the analysis of the data tools, both groups were indecisive in their attitudes (control group: 1.98; experimental group: 1.77), and the average of the experimental group $(\mathrm{X} 1=53.5)$ and the mean of the control group $(\mathrm{X} 2=52.75)$, it was concluded that there was no significant difference $(\mathrm{p}<0.05)$. The data of the data collection tools were analyzed and the teaching strategy to develop it was decided accordingly. The plans prepared in the implementation phase of the study were implemented. The application process carried out in the experimental and control groups for 3 weeks. According to results of attitude scale and interview data, the problems experienced by the target audience could be minimized. According to the results, robotic coding activities increased the academic achievement of students, provided positive attitude towards robotics, but did not affect the attitude towards programming. It was observed that the attitude scores towards programming in the experimental group increased more than the control group. In the light of all these results, it has been seen that the use of robotic kits in programming can be effective and beneficial.
\end{abstract}

Keywords: Education, programming, robotic kits

DOI: $10.7176 / \mathrm{JSTR} / 6-10-06$

\section{Ortaokulda Robotik Kitlerin Yardımıyla Programlamayı Öğretmek: Döngülerin ve Koşulların Somut Deneyimi}

Özet

$\mathrm{Bu}$ çalışmanın temel amacı, ortaokul eğitiminde kodlama öğretiminde yaşanan sorunların kaynağını bilgi teknolojileri ve yazılım dersi ile belirlemek ve ortadan kaldıracak çalışmalar planlamaktır.

72 | P a g e

www.iiste.org 
Öncelikle problemi ortaya çıkarmak için öğrencilerle görüşmeler yapılmış ve öğrencilerin en çok "döngüler" ve "koşullar" konusunda zorluk yaşadıkları ve bu konuları kavrayamadıkları ortaya çıkmıştır. Daha sonra durumun akademik yansımaları için başarı testi uygulanmış ve öğrencilerin tutumlarını belirlemek için tutum ölçeği uygulanmıştır. Toplanan bu veriler analiz edildi ve ihtiyaçlar belirlendi. Problemin çözümüne yönelik literatür taraması ile öğrencilerin yaşı, hazırbulunuşluk düzeyi, ortamı ve maliyeti gibi faktörler dikkate alınarak robotik uygulamaların dahil edilmesine karar verilmiştir. Araş̧ırmada öğretilecek gruplar belirlenmiş, geçerliği ve güvenirliği sağlanmış ölçme araçlarına yer verilmiştir. Çalışmaya 25 öğrenci, 1 deney grubu ve 1 kontrol grubundan oluşan toplam 50 öğrenci katılmıştır. Bu süreçte veri toplamak için kontrol grubuna tutum ölçeği ve programlamaya yönelik başarı testi, deney grubuna ise robotik tutum ölçeği ve başarı testi uygulanmıştır. Veri araçlarının analizi sonucunda her iki grup da tutumlarında (kontrol grubu: 1.98; deney grubu: 1.77), deney grubu ortalamasinda $(X 1=53.5)$ ve kontrol grubunun ortalamasinda $(X 2=52.75)$, anlamlı bir fark olmadığı sonucuna varılmıştır $(\mathrm{p}<0.05)$. Veri toplama araçlarının verileri analiz edilmiş ve onu geliştirecek öğretim stratejisine buna göre karar verilmiştir. Çalışmanın uygulama aşamasında hazırlanan planlar uygulandı. Uygulama süreci 3 hafta süreyle deney ve kontrol gruplarında gerçekleştirildi. Tutum ölçeği ve görüşme verilerinin sonuçlarına göre hedef kitlenin yaşadığı sorunlar en aza indirilebilir. Elde edilen sonuçlara göre robotik kodlama etkinlikleri öğrencilerin akademik başarısını artırmış, robotiklere karşı olumlu tutum sağlamış ancak programlamaya yönelik tutumu etkilememiştir. Deney grubunda programlamaya yönelik tutum puanlarının kontrol grubuna göre daha fazla arttığı görülmüştür. Tüm bu sonuçlar ışığında programlamada robotik kit kullanımının etkili ve faydalı olabileceği görülmüştür.

Anahtar Kelimeler: Eğitim, programlama, robotik kitler

\section{Giriş}

$\mathrm{Bu}$ çalışma, ilköğretim öğrencilerinin programlama dersindeki döngüler konusundaki başarılarının arttııılması amacıyla yapılmıștır. Bu çalıșmanın temel amacı ilköğretim bilişim teknolojileri ve yazılım dersinde yapılan kodlama öğretiminde yaşanan sorunların kaynağını tespit etmek ve bunu ortadan gidermeye yönelik çalışmalar planlamaktır. Problem tespitinde en sık kullanılan ve verimli olduğu kanttlanan yöntemlerden biri Görüşme tekniğidir (Ögel, 2009). Problemi ortaya çıkarmak için öğrenciler ile görüşme yapılmış ve öğrencilerin daha çok "döngüler" ve "koşullar" konusunda zorlandıkları ve bu konuları kavrayamadıkları ortaya çıkmıştır. Analiz süreci aşamasında problem durumunu tespit amacıyla öncelikle öğrencilerle görüşmeler yapılmıştır. Görüşmeler sonucunda öğrencilerin döngü ve koşul ifadesi içeren yapılarda zorlandıkları sonucuna ulaşılmıştır. Analiz sürecinde öğrencilerin döngüler konusunda neden zorlandıklarının ortaya çıkarılması amaçlanmıştır. Programlama konusunda öğrencilerin en çok döngüler ve koşullar konusunda zorlandıkları ve başarı testlerinde en düşük sonuçların da bu konuda olduğu görülmüştür. Görüşme sorularında da sebep olarak karmaşık ve zor olması sonuçlarına ulaşılmıştır. Tekrar yaparak, arkadaşlarından yardım alarak, öğretmenlerin rehberlik etmesi gibi ifadeler ise çözüm önerileri olarak ortaya çıkmıştır. Planlama aşamasında veri toplama araçları geliştirilmiştir. Bu çalışma kapsamında ihtiyaç değerlendirmesi yapılırken hedef kitleye 3 farklı ölçme aracı uygulanarak veriler toplanmıştır. Bu araçlar görüşme, başarı testi ve tutum ölçeğidir. Görüşme soruları "Code.org" ortamında gerçekleştirilen programlama uygulaması hakkındaki görüşleri elde edebilmek için hazırlanmıştır. Durumun akademik yansımaları için bir başarı testi uygulanmış ve öğrencilerin tutumlarının tespiti için tutum ölçeği uygulanmıştır. Toplanan bu veriler analiz edilmiş ve ihtiyaçlar belirlenmiştir. Sorunun çözümü için bilgisayar bilimlerinde robotik uygulamalara yer verilmesi ile ilköğretim öğrencilerinin soyut kavramları somutlaştırabilmesine, proje tabanlı ve işbirlikçi çalş̧abilmesine, kodlamadaki zor ve karmaşı kazanımları elde etmede motive olmasına, akademik başarıyı arttırmasına ve dersin eğlenceli hale gelmesine katkı sağladığı görülmüştür (Bers $v d$., 2014; Elkin $v d$., 2016). Bu yüzden hem öğrencilerin yaşları hem de alanyazında soyut kavramların öğretiminde robotik kitlerin katkısı göz önünde bulundurularak robotik kitlerle bir öğretim ortamı tasarlanmasına karar verilmiştir. Bu şekilde hem öğrencilerin kodlama konusunda yaşadıkları problemlerin giderilmesi, hem de konuya karşı olumlu bir tutum geliştirilmesi hedeflenmiştir.

$\mathrm{Bu}$ çalışmanın uygulama kısmı 3 hafta ve her hafta için dört ders saati şeklinde planlanmıştır. Uygulanma sürecinde kontrol grubu ve deney grubunda aynı kazanımlar farklı yollarla edindirilmeye çalışılııştır. Kontrol grubunda laboratuvar ortamında scratch etkinlikleri yapılırken deney grubunda yine laboratuvar ortamında robotik uygulamalara yer verilmiştir. Dersler her iki grupta da genel olarak

73 | P a g e

www.iiste.org 
bilinenden bilinmeyene, basitten karmaşığa, kolaydan zora şeklinde sunulmuştur. Bu aşamalarda Gagne'nin 9 adım ilkelerine de yer verilmiştir. Öğretim sırasında ağırlıklı olarak doğrudan ve etkileşimli stratejilere yer verilmiştir. Etkileşimli öğretim stratejileri öğrencilerin derse ilgisini artırmaktadır (Akay $v d$., 2016). Öncelikle sözel bilgiler eğitmen tarafindan sunulmuş ve genel olarak tümden gelim yaklaşımı kullanılmıştır. Etkileşimli stratejilerin kullanılması sırasında ise tartışma ve beyin firtınası teknikleri uygulayarak eğitmen ve öğrenenler arasında etkili bir iletişim ortamı sağlanmıştır. Öğretimin ölçme ve değerlendirme bölümünde ise başarı testi ve robotiğe karşı tutum ölçeği ile programlamaya yönelik tutum ölçeği uygulanmıştır. Elde edilen tüm sonuçlar analiz edip yorumlanarak sonuçlar bölümünde detaylıca açıklanmıştır. Öğrencilerin, blok tabanlı kodlama yardımıyla somutlaştırılmış etkinlikler ile birlikte algoritma mantığını daha iyi kavraması beklenmektedir (Başer, 2013). Bu çalışmada algoritmik düşünme becerilerinin sağladığı problem çözme, analitik düşünme, mantıksal düşünme gibi üst düzey düşünme becerilerin gelişmesi, günlük hayatta yer alan olaylara daha farklı bakış açılarıyla ele almasının sağlanması amaçlanmaktadır.

Çalışma kapsamında hazırlanan ve uygulanan öğretimin hedefi; öğrencilerin programla başarısını arttırmak ve programlama ile robotik kodlamaya yönelik olumlu tutum kazandırmaktır. Yapılan çalışmalar, mBlock programlama ortamı ve mBot robot kullanılarak programlama öğretiminde; döngüler, koşul yapıları, fonksiyonlar-prosedürler, değişkenler, listeler ve diziler gibi programlamanın temel kavramlarını içeren uygulamaların kolayca oluşturulup kullanılabileceğini göstermektedir (Numanoğlu ve Keser, 2017). Çalı̧̧mada kullanılan öğretim yöntemi belirlenirken öğrenciler ile yapılan görüşmeler sonucunda öğrenciler; tekrar ederek, arkadaşları ile yardımlaşarak, öğretmenin rehber olması gibi durumlarda daha iyi öğrenebileceklerini ifade etmişlerdir. Bu doğrultuda çalışmada daha önce bireysel olarak yapılan derslerin bu süreçte grup halinde yapılması kararlaştırılmış, işbirlikçi öğrenme ortamlarına yer verilmiştir. Alanyazına bakıldığında eğitim ortamlarında robotik etkinliklere yer verilmesinin öğrencileri işbirlikli öğrenmeye yönelttiği ve öğrenme aktivitelerine olan isteklerini artırmada etkili olduğu görülmüştür (Chen $v d$., 2011; Highfield, 2010). Bu şekilde öğrencilerin akran desteği alabilmesi, yapamadıkları bölümleri gözlemleyerek tekrar yapabilmesi ve öğretmenin gruplara, bireylere oranla daha sık uğrayabilmesi amaçlanmıştır. Öğrencilerin hem işbirlikçi bir şekilde öğrenebilmesi hem de ders sürecinde yer alan uygulamaların grup çalışmasıyla yapılabilmeye uygun olmasından dolayı proje tabanlı öğretim yöntemine yer verilmiş̧ir.

\section{Yöntem}

İlköğretim bilişim teknolojileri ve yazılım dersinde yapılan kodlama öğretiminde yaşanan sorunların kaynağını tespit etmek ve bunu ortadan gidermeye yönelik çalışmalar planlayarak uygulamak amacıyla yapılan bu çalışmada karma araştırma yöntemi benimsenmiştir. Sorunun tespiti aşamasında nitel yöntem kullanılırken uygulanan öğretim aşamasında nicel yöntem kullanılımıştır. Deney ve kontrol gruplarına uygulanan ölçekler karşılaştırmalı $\mathrm{T}$ testleriyle analiz edilmiştir. Çalışmada öncelikle sorunun belirlenmesi için nitel veriler üzerine odaklanılmıştır. Nitel araştırmada araştırmacı gözlem, görüşme ve doküman analizi gibi nitel veri toplama yöntemlerini kullanarak, algıların ve olayların doğal ortamda gerçekçi ve bütüncül bir biçimde ortaya koymaya ve yorumlamaya çalışmaktadır (Yıldırım ve Şimşek, 2016). Nitel yaklaşım çerçevesinde veri toplama tekniği olarak görüşmelerin yapılması; veri analiz yöntemi olarak da içerik analizinden yararlanılmıştır. İçerik analizi toplanan verileri açıklayabilecek kavramlarla ilişkilendirme sürecidir. Bu süreç verilerin kodlanması, temaların bulunması, kodların ve temaların düzenlenmesi, bulguların tanımlanması ve yorumlanması olmak üzere dört aşamadan oluşmaktadır (Yıldırım ve Şimşek, 2016).

Planlama aşamasında veri toplama araçları geliştirilmiştir. $\mathrm{Bu}$ çalışma kapsamında ihtiyaç değerlendirmesi yapılırken hedef kitleye 3 farklı ölçme aracı uygulanarak veriler toplanmıştır. Bu araçlar görüşme, başarı testi ve tutum ölçeğidir. Bu ölçeklerin analizi T testleri kullanılarak yapılmıştır. Görüşme soruları "Code.org" ortamında gerçekleştirilen programlama uygulaması hakkındaki görüşleri elde edebilmek için hazırlanmıştır. Görüşmede öğrencilere bu uygulamada neleri beğendikleri, beğenmediği kısımları, uygulamada hangi kısımlarda zorlandıkları ve bu zorlukların üstesinden nasıl geldikleri sorulmuştur. Diğer bir veri toplama aracı olan başarı testinde ise "döngüler" konusunda görsel sorulara yer verilmiştir. Bu sorular hazırlanırken döngüler konusunun tüm kapsamına yer verilmeye ve özellikle öğrencilerin anlamakta zorlandığı kısımlardan oluşturulmaya araştırmacı tarafindan özen gösterilmiştir. Öğrencilerin programlamaya yönelik algılarını ortaya koymak için ise 47 maddelik programlamaya karşı tutum ölçeği kullanılmıştır. Ölçek, literatürde bulunan bilgisayar programlama karşı tutum ölçeği geliştirme çalışması isimli makaleden alınmıştır. Ölçme araçları öğretimin amaçlarına ne oranda ulaşıldığını ortaya koyan yardımcı araçlardır (Şimşek, 2009). Çalışma

74 | P a g e

www.iiste.org 
kapsamında her biri 25 kişiden oluşan, 1'i deney ve 1'i kontrol grubu olmak üzere toplam 50 öğrenciye yer verilmiştir. Bu süreçte veri toplamak amacıyla kontrol grubunda programlamaya yönelik tutum ölçeği ve başarı testi uygulanırken deney grubunda programlamaya yönelik tutum ölçeği ile birlikte robotik tutum ölçeği ve başarı testi uygulanmıştır. Çalışma kapsamında, her iki grup için de ölçme aracı olarak başarı testi ön test hazırlanmıştır. Ön testte her öğrenme basamağında soruların yer almasına, kapsam geçerliğinin sağlanmasına ve döngü ile karar yapıları içeren sorulara yer verilmiştir. Ölçekte yer alan sorular Şimşek (2018) tarafindan hazırlanmış, geçerlik ve güvenirlikleri sağlanmıştır. Robotik uygulamalara yer verilen deney grubunda robotik tutum ölçeği uygulanmıştır. Ortaokul öğrencilerinin robotiğe karşı tutumunu belirlemek amacıyla Cross, Hammer, Zito, Nourbakhshh ve Bernstein (2016) tarafindan hazırlanan ölçeğin Türkçe uyarlaması ve geçerlik güvenirlik çalışmaları 2018 yılında Şişman ve Küçük tarafından yapılmıştır. Robotik uygulamalara yer verilmeyen, yalnızca scratch aracının kullanıldığ kontrol grubunda ise programlamaya yönelik tutum ölçeği kullanılmıştır.

Çalışmada kullanılan 3 ölçek içinde veri analizleri uygun yöntemlerle gerçekleştirilmiştir. Araştırmacının bir dönem boyunca ders sürecinde öğrencilerin blok tabanlı kodlama aracının 2. ve 3 . bölümlerinde zorlanmalarını gözlemlemesi sonucu problem durumunu analiz etme ihtiyacı doğmuştur. Görüş̧meler sonucunda öğrencilerin döngü ve koşul ifadesi içeren yapılarda zorlandıkları sonucuna ulaşılmışıır. Bu doğrultuda yapılan alanyazın taramasında programlamaya yönelik tutum ve karmaşıklık (Jenkins, 2002) ile programlama öğretiminde kullanılan yöntem ve tasarımın (Mayer, 1976) başarıyı etkilediği sonucuna ulaşılmıştır. Alanyazın taraması sonucunda geçerlik ve güvenirliği sağlanmış bir programlamaya yönelik tutum ölçeği ile başarı testi uygulanmıştır. Tutum ölçeğinin ögrenci seviyesine uygun ortaokul düzeyinde olmasına ve başarı testinde yer alan soruların ise döngü ifadeleri içermesine dikkat edilmiş, bu konuda danışman onayı alındıktan sonra uygulama gerçekleştirilmiş. Akademik başarıyı ölçme bağlamında çalışmada yapılan uygulamalar sonucunda deney ve kontrol gruplarının akademik başarıları arasında meydana gelen değişimin karşılaş̧ırılması için "bağımsız gruplar $t$ testi" yapılmıştır. Programlamaya Yönelik Tutum ölçeği için de çalışmada yapılan uygulamalar sonucunda deney ve kontrol gruplarının programlamaya yönelik tutumları arasında meydana gelen değişimin karșılaştırılması için "bağımsız gruplar t testi" yapılmıştır. Çalışmada yapılan robotik kodlama etkinlikleri sonucunda deney grubunun robotiğe yönelik tutumunda meydana gelen değişimin karşılaş̧ırılması için "bağımlı gruplar $t$ testi" yapılmıştır. Bütün analiz sonuçları detaylı şekilde açıklanmıştır.

\section{Bulgular}

Çalışma kapsamında yapılan veri analiz sonuçlarına göre programlama dersinde hedef kitlenin daha çok "döngüler" ve "koşullar" konusunda zorlandıkları ve bu konuları kavrayamadıkları ortaya çıkmıştır. Sorunun çözümü için yapılan alanyazın taraması ile birlikte öğrencilerin yaşı, hazırbulunuşluk düzeyi, ortam, maliyet gibi faktörler de göz önünde bulundurularak robotik uygulamalara yer verilmesine karar verilmiştir. Bu etkinlikler kapsamında ulaşılan sonuçlar aşağıda sunulmuştur.

\subsection{Akademik başarı}

Çalışmada yapılan uygulamalar sonucunda deney ve kontrol gruplarının akademik başarıları arasında meydana gelen değişimin karşılaştırılması için "bağımsız gruplar t testi” yapılmıştır (Tablo 1).

Tablo 1. Deney ve Kontrol Grubu Başarı Testi Sonuçları

\begin{tabular}{lllllll}
\hline Gruplar & $\mathrm{N}$ & $\overline{\mathrm{X}}$ & $\mathrm{ss}$ & $\mathrm{sd}$ & $\mathrm{t}$ & $\mathrm{p}$ \\
\hline Kontrol & & & & & & \\
Grubu & 24 & 53.83 & 18.64 & 3.80 & & \\
& & & & & & \\
Deney & & & & & -2.312 & 0.025 \\
Grubu & 24 & 65.58 & 16.49 & 3.36 & & \\
\hline
\end{tabular}

75 | P a g e 
Tablo 1 incelendiğinde deney grubu başarı testi ortalaması $(\overline{\mathrm{X}}=65.58)$ ile kontrol grubu başarı testi ortalaması $(\overline{\mathrm{X}}=53.83)$ arasındaki fark istatistiksel olarak anlamlıdır $(\mathrm{p}<0.05)$. Bu sonuç robotik kodlama etkinliklerinin öğrencilerin akademik başarıları üzerinde olumlu etkileri olduğunu göstermektedir.

\subsection{Programlamaya Yönelik Tutum}

Çalışmada yapılan uygulamalar sonucunda deney ve kontrol gruplarının programlamaya yönelik tutumları arasında meydana gelen değişimin karşılaştırılması için "bağımsız gruplar t testi” yapılmıştır. Sonuçlara yönelik bulgular Tablo 2.’de verilmiştir.

Tablo 2. Deney ve Kontrol Grubu Programlamaya Yönelik Tutum Ölçeği Sonuçları

\begin{tabular}{lllllll}
\hline Gruplar & $\mathrm{N}$ & $\overline{\mathrm{X}}$ & $\mathrm{ss}$ & $\mathrm{sd}$ & $\mathrm{t}$ & $\mathrm{p}$ \\
\hline Kontrol & & & & & & \\
Grubu & 24 & 1,59 & 0.29 & 0.6 & & \\
& & & & & & \\
Deney & 24 & 1,44 & 0.27 & 0.5 & & \\
Grubu & & & & & & \\
\hline
\end{tabular}

Tablo 2'ye bakıldığında deney grubu tutum ortalaması $(\overline{\mathrm{X}}=1,44)$ ile kontrol grubu tutum ortalamas $(\overline{\mathrm{X}}=1,59)$ sonucu gruplar arasında oluşan fark istatistiksel olarak anlamlı değildir $(\mathrm{p}>0.05)$. Bu sonuç robotik kodlama etkinliklerinin öğrencilerin programlamaya yönelik tutumlarında etkili bir fark yaratmadığını göstermektedir. Buna sebep olarak tutum puanlarının kısa sürelerde çok fazla değişime uğramadığı ancak yeterli zaman verildiğinde olumlu yönde artış gözlemlenebileceği gösterilebilir.

\subsection{Robotik Tutum}

Çalışmada yapılan robotik kodlama etkinlikleri sonucunda deney grubunun robotiğe yönelik tutumunda meydana gelen değişimin karşılaştırılması için "bağımlı gruplar t testi” yapılmıştır. Sonuçlara yönelik bulgular Tablo 3.’te verilmiştir.

Tablo 3. Deney grubunun robotiğe yönelik tutumunda meydana gelen değişim

\begin{tabular}{lllllll}
\hline Testler & $\mathrm{N}$ & $\overline{\mathrm{X}}$ & $\mathrm{ss}$ & $\mathrm{sd}$ & $\mathrm{t}$ & $\mathrm{p}$ \\
\hline Ön test & 24 & 1,78 & 0.33 & 0.6 & & \\
Son test & 24 & 1,41 & 0.37 & 0.7 & & \\
\hline
\end{tabular}

Tablo 3 incelendiğinde deney grubunun robotiğe yönelik ön test puan ortalaması $(\overline{\mathrm{X}}=1,78)$ ile son test puan ortalaması $(\overline{\mathrm{X}}=1,41)$ arasındaki fark istatistiksel olarak anlamlıdır $(\mathrm{p}<0.05)$. Programlamaya yönelik tutumda değişiklik olmazken robotiğe yönelik tutumda anlamlı bir farkın meydana gelmesi robotik kodlama etkinliklerinin öğrenciler tarafından sevilmesinden veya öğrencilerin ilk defa robotik kitleri kullanmasından dolayı yenilik etkisi yaratmasından da kaynaklanabilmektedir.

\section{Tartışma ve Sonuç}

Analiz aşamasında hedef kitleye veri toplama ölçekleri uygulanmış ve bu ölçeklerin sonucunda hedef kitlenin döngüler ve koşul yapıları konularında zorlandıkları belirlenmiştir. Aynı zamanda öğrenciler yapılan görüşmelerde zorlandıkları kısımları arkadaşları ile yardımlaşarak, tekrar deneyerek ve eğitimcinin daha çok rehberlik etmesi ile aşabileceklerinin ifade etmişlerdir. Bu doğrultuda işbirlikçi öğrenme ile proje tabanlı öğretim yöntemlerine başvurulmuş ve eğitmenin rol aldı̆̆ Gagne'nin dokuz aşamalı öğretim yaklaşımı işe koşulmuştur. Öğretim tasarımı sürecinde analiz 76 | P a g e www.iiste.org 
aşamasında elde edilen sonuçlara bakılarak belirlenen problemin robotik uygulamalar ile giderilmesine karar verilmiştir. Verilen bu karar doğrultusunda geliştirilen 3 haftalık öğretim programı hedef kitle olan deney ve kontrol gruplarına uygulanmıştır. Tutum ölçeği ve görüşme verileri incelendiği zaman hedef kitlenin yaşanılan problemlerin minimum düzeye inebileceği tespit edilmiştir. Elde edilen sonuçlara göre robotik kodlama etkinliklerinin öğrencilerin akademik başarılarını arttırdığı, robotiğe yönelik olumlu tutum gelişmesini sağladığı ancak programlamaya yönelik tutumu etkilemediği görülmüştür. Deney grubunda programlamaya yönelik tutum puanlarının kontrol grubuna göre daha çok arttığı gözlemlenmiştir. Çalışmada kullanılan etkinliklerin etkili olduğu ancak yeterli zaman verildiğinde daha etkili sonuçların elde edilebileceği düşünülmektedir. Ayrıca çalışmada kullanılan robot kit sayısının daha fazla olmasının sonuçların daha iyi olmasında etkili olabileceği düşünülmektedir. Çünkü araştırmacının gözlemlerine göre uygulama sürecinde öğrencilerin bir kısmının daha az kişiyle veya tek başına çalışmak istedikleri görülmüştür.

Öğrenciler daha önce bir dönem code.org platformunda kodlama eğitim almışlardır. Yapılan görüşmelerde öğrencilerin bu ortamları sevdikleri ancak döngü ve karar yapıları içeren kısımlarda zorlandıkları için bu bölümleri sevmedikleri ortaya çıkmıştır. Bu amaçla uygulama yine öğrenci seviyesine ve yaşına uygun olan blok tabanlı bir kodlama aracı "Scratch" ve "Mblock" ile gerçekleştirilmiş ve kazanımlar kolaydan zora, basitten karmaşığa doğru sıralanarak hazırlanmıştır. Her iki uygulama da k12 düzeyine uygun olan platformlardır. Döngü ve karar yapılarındaki zorluklar ile birlikte öğrenciler karakterlerin yönlendirilmesinde de sorun yaşadıklarını ifade etmişlerdir. Kodlama öğretiminde gerçekçi uygulamalar yapılması soyut kavramları somutlaştırmakta, motivasyonu arttırmakta ve ögrrenmeyi kolaylaştırmaktadır (Kuşdemir, 2019). Bu sebeple çalışmada robotik kodlama etkinliklerine yer verilmesine karar verilmiştir.

Grup çalı̧̧malarda kimi zaman bazı öğrenciler pasif konumda sadece izleyerek zaman geçirebilmekte, baskın kişilerce geri plana itilebilmekte veya yeterli zaman bulamayabilmektedir (Ratnawati, 2020). Bu amaçla çalışmada gruplar oluşturulurken akademik başarısı düşük ve yüksek öğrenciler sınıfta standart bir ortalama oluşturulmuş şekilde bir araya getirilmişlerdir. Bu çalışmada Döngüler ve Koşullar gibi soyut programlama konuların öğrencilerin oldukça ilgisini çeken Robotlarla somtlaştırılarak öğretimi yapılmış ve faydalı olduğu görülmüştür. Öğrencilerin derse ilgisini çekmek ve bu ilgiyi canlı tutmak amacıyla ders girişlerinin ülkemizde ve dünyada robotik ile ilgili yaşanan gelişmeleri sunan kısa videolar izlettirilmesi ile birlikte ders sürecinde yapılan etkinliklerin günlük yaşam aktiviteleriyle bağlantı kurularak aktarılması önerilmektedir.

\section{Kaynaklar}

Akay, Y., Çırakoğlu, M., \& Yanar, B. H. (2016). Ortaokul 5. ve 6. sınıf öğrenci ve öğretmenlerinin seçmeli derslere ilişkin görüşleri. İlköğretim Online, 15(1), 1-22.

Başer, M. (2013). Bilgisayar programlamaya karşı tutum ölçeği geliştirme çalışması. The Journal of Academic Social Science Studies, 6(6), 199-215.

Bers, M. U., Flannery, L., Kazakoff, E. R., \& Sullivan, A. (2014). Computational thinking and tinkering: Exploration of an early childhood robotics curriculum. Computers \& Education, 72, 145-157.

Kuşdemir, Y. (2019). İlkokul Öğrencilerinin Sözcük Öğrenme Motivasyon ve Okuduğunu Anlama Düzeylerinin İncelenmesi. Avrasya Uluslararası Araştırmalar Dergisi, 7(16), 962-979.

Chen, G., Shen, J., Barth-Cohen, L., Jiang, S., Huang, X., \& Eltoukhy, M. (2017). Assessing elementary students' computational thinking in everyday reasoning and robotics programming. Computers \& Education, 109, 162-175.

Cross, J., Hamner, E., Zito, L., Nourbakhshh, I., \& Bernstein, D. (2016, October). Development of an assessment for measuring middle school student attitudes towards robotics activities. In Frontiers in Education Conference (FIE), 2016 IEEE (pp. 1-8). IEEE. 
Çankaya, S.,\& Karamete, A. (2008). Eğitsel bilgisayar oyunlarının öğrencilerin Matematik dersineve eğitsel bilgisayar oyunlarına yönelik tutumlarına etkisi. Mersin Üniversitesi Ĕ̆itim Fakültesi Dergisi, 4 (2), 115-127.

Elkin, M., Sullivan, A., \& Bers, M. U. (2016). Programming with the KIBO robotics kit in preschool classrooms. Computers in the Schools, 33(3), 169-186.

Highfield, K. (2010). Robotic toys as a catalyst for mathematical problem solving. Australian Primary Mathematics Classroom, 15(2), 22-27.

Numanoğlu, M., \& Keser, H. (2017). Programlama öğretiminde robot kullanımı-mbot örneği. Bartin Üniversitesi Egitim Fakültesi Dergisi, 6(2), 497.

Jenkins, T. (2002). On the difficulty of learning to program. In 3rd annual Conference of LTSNICS, Loughbrorough University, Leicestershire, UK.

Mayer, R. E. "Some conditions of meaningful learning for computer programming: Advance organizers and subject control of frame order". Journal of Educational Psychology, 68 (2), pp. 143-150. (1976)

Şimşek, E. (2018). Programlama öğretiminde robotik ve scratch uygulamalarinin öğrencilerin bilgi işlemsel düşünme becerileri ve akademik başarilarina etkisi. (Yüksek Lisans Tezi), Yükseköğretim Kurulu Ulusal Tez Merkezi’nden edinilmiştir. (Tez No. 519321)

Şimşek, N. (2009). Sosyal bilgilerde ölçme ve değerlendirme. Mustafa Safran Sosyal Bilgiler Ögretimi. Pegem Akademi, ss, 571-624.

Şişman, B., \& Küçük, S. (2018). Ortaokul Öğrencilerine Yönelik Türkçe Robotik Tutum Ölçeğinin Geçerlik ve Güvenirlik Çalışması. Ege Eğitim Dergisi, 19(1), 284-299.

Ögel, K. (2009). Motivasyonel görüşme tekniği. Türkiye Klinikleri Journal of Psychiatry-Special Topics, 2(2), 41-4.

Ratnawati, S. (2020). Öğrenci Merkezi Öğreniminin Örgütsel Davranış Dersinin Harmanlanmış Öğrenme Yöntemi ile Uygulanması. Soedirman Ekonomi Ĕ̆itimi Dergisi, 2 (1), 85-96.

Yıldız, M. (2018). Oyunlaştırılmış blok tabanlı algoritmik düşünme etkinliklerinin öğrencilerin programlamaya yönelik tutum, katılım ve becerilerine etkisi. (Yüksek Lisans Tezi), Yükseköğretim Kurulu Ulusal Tez Merkezi'nden edinilmiştir. (Tez No. 513250) 